\title{
Ismael del Pan (1889-1968). Arqueología, etnografía, educación y política en la primera mitad del siglo $\mathrm{XX}$
}

\author{
Ismael del Pan (1889-1968). Archaeology, Ethnography, \\ Education and Politics in the first half of the 20th century
}

\begin{abstract}
Jorge DE TORRES RODRÍGUEZ
Departamento de Prehistoria, Facultad de Geografía e Historia, Universidad Complutense de Madrid. jorgedetorres@yahoo.es
\end{abstract}

Recibido: 27-09-2010

Aceptado: 04-01-2011

\section{RESUMEN}

La vida del arqueólogo y etnógrafo Ismael del Pan (1889-1968) sirve como guía para realizar un recorrido por las estructuras académicas y educativas de tres periodos de nuestra historia reciente (Monarquía, República y dictadura franquista) y sobre la forma en que se imbricaron y transformaron política, ciencia y educación en la España de la primera mitad del siglo XX. De origen humilde, Ismael del Pan aprovechó al máximo las posibilidades que le ofrecieron las reformas educativas de comienzos de siglo, desarrolló una intensa actividad investigadora desde su puesto como profesor de Instituto, colaborando con personalidades como Paul Wernert, Francisco Hernández-Pacheco o Luis de Hoyos y sufrió directamente la convulsa situación política española del final de la Monarquía, la República y la Guerra Civil. Su vida ejemplifica perfectamente las condiciones, capacidades y expectativas del conjunto de investigadores españoles de este periodo que, sin constituir figuras de primer orden, contribuyeron con su trabajo a dignificar las maltrechas educación e investigación españolas del primer tercio del siglo pasado.

Palabras Clave: Historiografia. Educación. Arqueología. Etnografía. Siglo XX. España.

\begin{abstract}
Archaeologist and ethnographer Ismael del Pan's life (1889-1968) allows us to go through the academic and educational structures of three historical periods of Spain in the first half of the 20th century (Monarchy, Republic and Franco's dictatorship) and to see how politics, science and education were conceived and transformed during those turbulent years. Lowborn, Ismael del Pan took advantage of all the new educational reforms developed in the century's early decades and carried out an active academic career from his position as High Secondary School teacher, including partnership with high-level researchers as Paul Wernert, Francisco Hernández-Pacheco or Luis de Hoyos. He also witnessed and was personally affected by the political turmoil at the end of Monarchy, the Republic and the Spanish War of 1936-1939. Therefore, his life exemplifies the conditions, capacities and expectations of a group of researchers that, despite their secondary role in the scientific field, contributed to improve and dignify the fragile education and science of the country in that period.
\end{abstract}

KEY WORDs: History of research. Education. Archaeology. Ethnography. 20th century. Spain.

SUMARIO 1. Introducción. 2. Pobre y brillante: la etapa de formación. 3. Cursus Honorum. 4. La consolidación como investigador: Toledo. 5. Años difíciles: Barcelona y Albacete. 6. Depuración. 7. Conclusión en Madrid. 


\section{Introducción}

El proceso de revisión historiográfica realizado sobre la denominada Edad de Plata de la ciencia y cultura españolas ha centrado generalmente sus esfuerzos en visiones globales de las transformaciones de estos ámbitos a lo largo del primer tercio del siglo XX, en su destrucción durante la Guerra Civil y posterior represión o en las grandes personalidades del periodo (Fusi, J.P. 1999, Otero, L.E. 2001). Menos comunes han sido las aproximaciones a figuras de nivel medio que conformaron el grueso del colectivo estudiado y que paradójicamente han sido dejadas de lado en estos análisis.

Ciriaco Ismael del Pan Fernández (1889-1968) es uno de estos personajes (Fig. 1). Prehistoriador, paleontólogo y etnógrafo - dentro de la visión interrelacionada en que se concebían estas disciplinas en ese momento (Ortiz 2001:279)-, el análisis de su carrera nos permite abrir una ventana a las dinámicas de formación, promoción académica y ascenso científico y social establecidas antes de la Guerra Civil para la mayoría de investigadores, lejos de personalidades excepcionales como Hugo Obermaier o Pedro Bosch-Gimpera. Por otra parte, su posición política liberal moderada proporciona un valioso testimonio para comprender la complejidad de la situación política antes de la Guerra Civil, y las dificultades de integración de aquellos individuos que no encajaban en la división en dos bandos que impuso la sublevación militar de 1936.

Las fuentes directas utilizadas para este artículo provienen en su mayor parte del Archivo General de la Administración, que conserva casi todo el expediente académico de Ismael del Pan (legajo 5840 , expediente 2) y su expediente de depuración tras la Guerra Civil (legajo 18523, expediente 52). El Archivo Central del Ministerio de Educación conserva la información respectiva a su vida laboral como profesor del Instituto "Lope de Vega" de Madrid hasta su jubilación en 1959 (Caja 97-241 A). A través del excelente archivo digitalizado sobre la Junta de Ampliación de Estudios (http://archivojae.edaddeplata.org) hemos accedido a la información original referente a su solicitud de pensión para estancias en el extranjero y los resultados de la misma en Portugal. Asimismo, en el portal www.cervantesvirtual.com hemos accedido la información referente a la participación de Ismael del Pan en la Real Academia de la Historia durante sus años en Toledo.
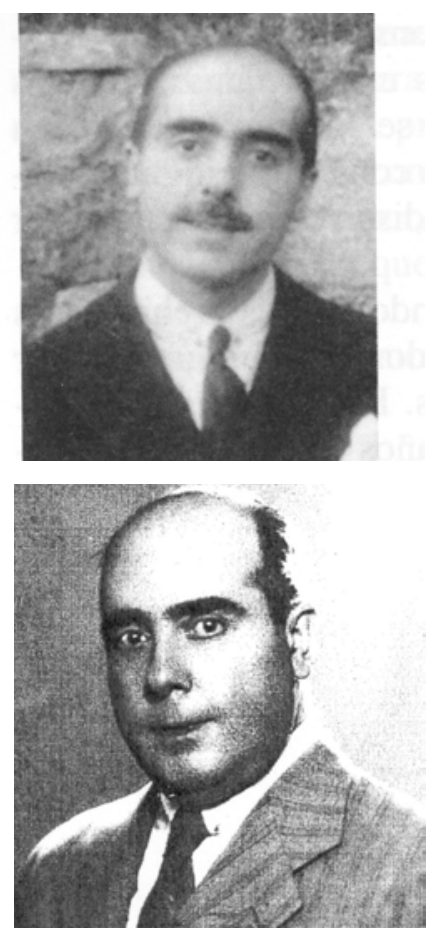

Figura 1.- Ismael del Pan, durante su estancia en Toledo en la década de 1920 y en 1943 a los 54 años de edad. (1 tomado de AA.VV., Biografias y Semblanzas de profesores. Instituto "El Greco" de Toledo (1845-1995), Toledo 1999, 2 del Archivo General de la Administración).

Menos suerte hemos tenido con otros archivos de instituciones con las que colaboró o en las que trabajó Ismael del Pan. El Museo de Historia Natural y la Real Sociedad de Historia Natural no conservan información sobre su trabajo y tampoco hemos podido acceder a la información de las actas de los Institutos Balmes, Lope de Vega y Cardenal Lorenzana de Toledo, donde Ismael del Pan ejerció la mayor parte de su vida. Los expedientes académicos completos suplen en gran medida este vacío y para el caso de Toledo contamos además con el único artículo escrito acerca de nuestro investigador (García 1999), que aporta información relevante acerca de su trabajo en la Real academia de Bellas Artes y Ciencias Históricas de Toledo. La información ha sido completada con las actas o resúmenes de actividades publicadas por instituciones como la Sociedad Española de Antropología, Etnografía y Prehistoria o la Real Academia de Bellas Artes y Ciencias Históricas de Toledo.

Aunque breves, se han realizado anteriormente algunas aproximaciones a la figura de Ismael del 
Pan. Además de la ya citada de Francisco García, centrada en su actividad en el Instituto de Toledo entre 1919 y 1931, su figura es reseñada en el estudio general que del mismo hace José María Ruiz (Ruiz 2005: 93-5). Finalmente, y debido a su doble faceta de prehistoriador y etnógrafo, su figura ha sido incluida tanto en el Diccionario Histórico de la Antropología Española (Ortiz 1994) como en el Diccionario Histórico de la Arqueología en España (Ortiz y Fernández 2009). Finalmente, la producción académica del autor ha sido otra valiosa fuente de información. A lo largo de su vida Ismael del Pan publicó más de sesenta artículos y libros que son la fuente primaria para analizar su formación, intereses y enfoques metodológicos. Se ha consultado, salvo algunas excepciones, la totalidad de su producción científica como parte de la adecuada contextualización del autor dentro de su época y de las corrientes de pensamiento en las que se formó y de las que participó.

\section{Pobre y brillante: la etapa de formación}

Nacido en Logroño el 22 de junio de 1889, de padre carpintero y madre ama de casa, en la España que entraba en el siglo XX una persona como Ismael del Pan tenía muy pocas posibilidades de acceder a la enseñanza superior. Su trayectoria sólo puede explicarse en el contexto de los cambios históricos que afrontó el sistema educativo español en el primer tercio del siglo XX como resultado de las corrientes regeneracionistas que triunfaron tras la crisis nacional de 1898. En este sentido, la fundación del Ministerio de Instrucción Pública y Bellas Artes en 1900 supone el inicio de un verdadero cambio en la reforma de la educación en España en todos sus niveles, destinado a remediar las enormes carencias de un ámbito en el que la última ley general (la Ley Moyano) databa de 1857, y al que, en última instancia, se achacaba la decadencia de España. Para hacernos una idea de la situación de la educación española en ese momento baste con señalar que en 1900 la tasa de analfabetismo era de un 63,8\% (Ruiz 2005: 13), que los maestros de primaria no tenían sueldo fijo $\mathrm{y}$ eran pagados por ayuntamientos y alumnos, $\mathrm{y}$ que en 1898 sólo existían 62 institutos de enseñanza secundaria en España (Gómez 2001: 426) de calidad muy desigual. Sólo la Universidad Central de Madrid podía otorgar títulos de Doctorado y disponía de las cinco facultades completas con que contaba el sistema universitario español, que en el curso 1900/1901 sólo acogió a algo más de 17.000 alumnos en toda España, de los que apenas 9.000 eran alumnos oficiales (Ruiz 2001: 432).

Numerosas iniciativas de los sucesivos ministros trataron de paliar en lo posible esta situación a través de una intensa y a menudo polémica actividad legislativa, que en un raro alarde de responsabilidad fue continuada por los diferentes gobiernos independientemente de su signo político (Puelles 2001: 8). En menos de tres años (hasta diciembre de 1902) se acometió la reforma de las Escuelas Normales, de la Segunda Enseñanza, se consiguió que el Estado se hiciera cargo definitivamente del pago de los maestros, se duplicó la edad escolar obligatoria y comenzaron programas como la política de pensiones para estudios en el extranjero (Puelles 2001: 6-9).

El emblema de esta lucha por la mejora de la educación fue sin duda la creación en 1907 de la Junta para Ampliación de Estudios e Investigaciones Científicas (JAE), verdadero órgano renovador de la enseñanza superior española durante sus 32 años de existencia. Instituciones creadas bajo su patronazgo, como el Centro de Estudios Históricos (CEH), el Instituto Nacional de Ciencias Físico-Naturales, la Residencia de Estudiantes o la Comisión de Investigaciones Paleontológicas y Prehistóricas (CIPP) se convirtieron pronto en referentes de una renovación de facto de la ciencia española, libres de las cortapisas de instituciones excesivamente conservadoras como la Universidad. Es común la asunción de que este esfuerzo continuado en el mantenimiento de la inversión educativa a lo largo de las tres primeras décadas del siglo y su sustancial aumento durante la Segunda República posibilitaron el acceso a la educación primaria, secundaria y universitaria de un porcentaje creciente de población. Hay, sin embargo, pocos ejemplos de cómo este esfuerzo institucional se combinó con el tesón personal para lograr una mejora sustancial del nivel educativo y de la calidad de vida de los ciudadanos.

Ismael del Pan es sin duda uno de esos ejemplos, y su carrera es el resultado tanto de su enorme capacidad académica como de los esfuerzos institucionales para mejorar los niveles educativos de la población. Esta realidad se hace patente en su expediente académico en el Instituto de Logroño -donde había estudiado con una beca municipal- 
en el que debajo de unas calificaciones impecables se especifica que no puede expedírsele el título por no haber podido satisfacer la cuota correspondiente. De nuevo, la ayuda del Ayuntamiento de Logroño será la que permita a Ismael del Pan continuar sus estudios universitarios en la Universidad Central de Madrid, matriculándose en la Facultad de Ciencias en el curso de 1907/08. Ignoramos qué razones le impulsaron a elegir esta facultad, pero lo cierto es que en ella encontró el lugar para que su capacidad de trabajo y su inquietud científica fueran reconocidas e integradas en el embrión de la incipiente Arqueología prehistórica de nuestro país.

Por otro lado, la Arqueología no era ajena al proceso de renovación científica que se desarrollaba en las instituciones pioneras del país, abandonando el campo del anticuarismo diletante para acometer una progresiva profesionalización a lo largo de las décadas de los años 20 y 30 . Este proceso no se desarrolló de manera unificada y desde muy temprano se aprecian dos tendencias -la arqueología que procedía de la tradición anticuarista y la nueva arqueología prehistórica- que no sólo diferían en sus enfoques cronológicos sino también en su vinculación a determinadas disciplinas (Epigrafía, Numismática y Filologías en el caso de la Arqueología; Ciencias Naturales en el caso de la Prehistoria). Ambas tenían también un fuerte componente ideológico relacionado con la postura de la Iglesia y los sectores más conservadores de la sociedad española respecto de las teorías darwinistas (Maier 2000: 58) y en el fondo no dejaba de ser otro terreno más del enfrentamiento global entre las diferentes posiciones ideológicas, políticas y sociales que conformaban la sociedad de la Restauración. Durante el primer tercio del siglo XX, la Arqueología prehistórica fue una opción minoritaria y en cierto modo "sospechosa" por su supuesto carácter materialista, identificada con sectores progresistas de la sociedad influidos por las teorías krausistas o positivistas (Peiró y Pasamar 1989-90: 19). Así, mientras la Arqueología clásica va a tener una rápida aceptación social por su carácter enraizado en las tradiciones eruditas de la Restauración, la consolidación de la Prehistoria como disciplina científica fue más lenta y tuvo que apoyarse en personalidades de clara adscripción católica (o directamente sacerdotes, como Obermaier o Breuil) para lograr su aceptación definitiva. Esta dicotomía era per- ceptible también en las iniciativas de la JAE relativas a la Arqueología, donde cada una de las dos tendencias tuvo su propio centro de referencia. La primera se estructuró en torno al CEH y a la cátedra de Arqueología de la Universidad Central, creada en una fecha tan temprana como 1900 , mientras que la CIPP -creada en 1910- y el Museo de Ciencias Naturales aglutinaron a los todavía escasos prehistoriadores del país.

La práctica arqueológica en España en las décadas anteriores a la Guerra Civil fue por tanto el resultado de la interrelación de tres tendencias de importancia variable dependiendo del contexto social y académico. La primera de ellas es la continuidad de las tradiciones eruditas y anticuarias decimonónicas, muy extendidas entre las clases medias y entendidas como un ejercicio intelectual y social. Esta tendencia es la más numerosa, vinculada a instituciones como la Real Academia de la Historia, las sociedades arqueológicas de carácter local u otras asociaciones de carácter lúdico (casinos, ateneos, etc.); en segundo lugar, el creciente número de arqueólogos profesionales vinculados a universidades, el Centro de Estudios Históricos o museos; y finalmente, el aún más reducido grupo de arqueólogos prehistoriadores, en su mayoría con formación profesional y generalmente relacionados con instituciones vinculadas a las Ciencias Naturales o a la Antropología.

En este contexto, Ismael del Pan destacó pronto como un excelente estudiante, obteniendo matrícula de honor en todas las asignaturas y licenciándose con sobresaliente en 1911. También continuaron sus penurias económicas: hay referencias a su participación en varios concursos literarios de la Cruz Roja en los que obtuvo premios y accésit que ayudaron a sufragar sus estudios en 1909 y 1910. Sin embargo, la coyuntura científica le fue favorable, al menos en los años inmediatamente posteriores al término de la carrera, y con el apoyo de Eduardo Hernández Pacheco y una subvención de la JAE consiguió trabajo en el Museo de Ciencias Naturales como ayudante del curso de mineralogía y para ordenar la colección de mineralogía y geología. Allí conoció a Paul Wernert y probablemente fue en este momento donde se desarrolló su interés por la investigación prehistórica y el trabajo de campo.

Las becas de la JAE no eran sin embargo cuantiosas y la realidad económica llevó a Ismael del Pan a la necesidad de obtener un puesto estable, 
aprobando en abril de 1912 la oposición a catedrático de Historia Natural y Fisiología de la Higiene del Instituto de Cáceres, en condición de numerario. La aceptación de este puesto tan apartado de los principales centros de investigación ejemplifica la realidad laboral de la inmensa mayoría de licenciados y doctores españoles en este periodo, para los que una plaza en los Institutos de Segunda Enseñanza era la única salida viable dada la escasez de plazas en la Universidad y en los incipientes centros de investigación. De manera indirecta, a nosotros nos sirve para entender cómo funcionaba el sistema de promoción en la enseñanza superior en la España del primer tercio del siglo XX.

\section{Cursus Honorum}

A comienzos del siglo XX las características e importancia de los Institutos de Segunda Enseñanza eran muy diferentes de las actuales. Salvo excepciones como Madrid, había un único Instituto por provincia donde se formaban los escasos alumnos que podían permitirse el traslado hasta la capital o el desembolso de libros y material, y donde se preparaban los aún menos alumnos que podrían dar el salto a la universidad. El instituto era realmente la institución en la que se formaban las mesocracias provinciales (Ruiz 2005), y esta situación convertía generalmente de los profesores de institutos en miembros de las clases medio-altas de las capitales de provincia donde desempeñaban su labor.

Por otro lado, la reorganización universitaria de Aureliano Linares a finales del siglo XIX aumentó las dificultades de acceso al profesorado universitario, lo que indirectamente provocó un auge de los Institutos de Segunda Enseñanza, convertidos entonces en el refugio de muchos licenciados de alto nivel que encontraban cerradas las puertas de la Universidad. Durante el primer tercio del siglo $\mathrm{XX}$, los Institutos fueron el escenario de largas carreras de promoción personal, ya que si bien el grueso de los profesores se acomodaba en su situación de miembros de la burguesía provincial, otros muchos no renunciaban a sus carreras investigadoras al obtener su plaza y trataban de buscar destinos favorables para continuar con su investigación. La separación, por tanto, entre catedráticos de instituto y profesorado universitario no era rígida y las cátedras de instituto eran a menudo el puesto desde el que se planeaba y ejecutaba el asalto a la universidad.

Por supuesto, dentro de los institutos había categorías, generalmente en función de su cercanía a grandes ciudades. Institutos como los de San Isidro o Cardenal Cisneros en Madrid o el Juan Balmes en Barcelona eran los más ambicionados por quienes deseaban preparar su ascenso académico y social. El traslado se obtenía -en teoría- por concurso de méritos, para lo que era parte esencial el reconocimiento de la labor investigadora y la iniciativa científica de los aspirantes, pero para que sus publicaciones fueran tenidas en cuenta en el proceso debían ser valoradas y calificadas como "de mérito" por los claustros de profesores u otras instituciones científicas. El expediente académico de Ismael del Pan es un excelente ejemplo de la continua solicitud de certificados que avalasen su producción científica.

A través de su hoja de servicios podemos observar que Ismael del Pan llegó al Instituto de Cáceres con la idea muy clara de no renunciar a sus intereses investigadores, $\mathrm{y}$, en la medida de lo posible, no pasar más tiempo de lo estrictamente necesario como docente en ese centro. Para ello, trató de activar sus contactos en Madrid buscando ser reclamado en la capital para colaborar con el Museo de Ciencias Naturales, a la vez que aceleró su producción académica para aumentar sus méritos de cara a los concursos oficiales. Mientras lo hacía, no dejó de solicitar el traslado a otros centros con objeto de ser confirmado como titular en la cátedra.

De este modo, y gracias al apoyo de Hernández Pacheco, consiguió permisos en 1912 y 1913 para terminar sus cursos de doctorado y en 1914 y 1915 se aprobó su ausencia en el Instituto de Cáceres para incorporarse al Instituto Nacional de Ciencias Físico-Naturales como agregado, haciéndose cargo de los cursos de Geología y Paleontología. También comienza a publicar sus primeros artículos, sólo o en colaboración con Paul Wernert, apreciándose desde ese momento una de sus características como investigador: la dispersión en los temas y zonas geográficas tratadas. Así, publicó artículos sobre hallazgos prehistóricos en cuevas de Logroño (Pan 1915) y Cáceres (Pan 1917a, 1917b; Pan y Wernert 1917), y algunos apuntes sobre representaciones de arte prehistórico en el arco mediterráneo (Pan y Wernert 1915). Asimismo, colaboró con Paul Wernert en la traducción y adaptación al castellano de El Hombre Fósil de Hugo 
Obermaier. Finalmente, sus estancias en Madrid sirvieron a Ismael del Pan para preparar su tesis doctoral, que con el título de Paleografia de los mamíferos cuaternarios más importantes de Europa y Norte de África fue defendida en 1919.

Pero si hay algo que ejemplifica de manera patente los deseos de escapar del ambiente de provincias que se respiraba en Cáceres es el impresionante listado de concursos en los que participó. En 1913 optó a plazas en Almería y Palma de Mallorca, en 1914 en Figueras y en 1915, aceptando ocupar una plaza de auxiliar que finalmente no logró, trata de entrar en el Instituto de San Isidro de Madrid. En 1916 opta a los de Burgos y Cartagena, en 1918 concursa para plazas en el Cardenal Cisneros de Madrid y en Jerez de la Frontera y en 1919 en Las Palmas, Huesca y Gerona.

El trabajo de Ismael del Pan acabó dando sus frutos: la obtención del título de doctor, sus crecientes publicaciones y sobre todo su colaboración con algunos de los investigadores más importantes del momento, como Eduardo Hernández-Pacheco, Paul Wernert o Hugo Obermaier, debió pesar en la Comisión evaluadora que el 22 de febrero de 1919 le concedió la plaza de catedrático en el Instituto de Toledo. La primera impresión es que había cambiado un instituto de provincias por otro, pero como veremos Toledo tenía poco que ver con Cáceres.

\section{La consolidación como investigador: Toledo}

A priori, las condiciones de una pequeña ciudad como Toledo no parecían muy diferentes a los de cualquier otra capital de provincia. Sin embargo, varios factores influían en que fuese un destino codiciado para los profesores con más deseos de continuar una carrera científica (Díaz 200:285). El primero de ellos era, obviamente su cercanía a Madrid, decisiva para muchos de los docentes más emprendedores, que veían en ella la posibilidad de mantener contacto con el ambiente científico de la capital y en ocasiones, tratar de dar el salto a la Universidad Central. De este modo, en el Instituto de Toledo enseñaron personalidades relevantes como Ventura Reyes Prósper, Luis de Hoyos Sainz, Julián Besteiro Fernández o posteriormente el mismo Ismael del Pan, muchos de ellos intelectuales de primer nivel que no renunciaron a sus carreras investigadoras y que aportaron nuevas metodologías, ideas y un mayor nivel científico a las instituciones culturales de la ciudad, potenciando su actividad intelectual. Asimismo, desde las instituciones de ámbito estatal radicadas en Madrid se aprecia también un interés creciente por Toledo que se refleja en los artículos sobre Geología publicados en el Boletín de la Sociedad de Historia Natural o los estudios sobre epigrafía romana, hebrea y mozárabe toledanas que aparecen de manera recurrente en el Boletín de la Real Academia de la Historia.

En segundo lugar, Toledo contaba con instituciones específicas como la Academia de Infantería y la Catedral Primada de España, que aseguraban la presencia de un conjunto de personas de un nivel educativo y social medio/alto -fueran profesores de la Academia militar o sacerdotes relacionados con el Arzobispado-, con una situación económica desahogada y cierta predisposición hacia la discusión erudita y la actividad intelectual, o al menos hacia el componente social que éstas representaban. No puede olvidarse que la presencia de militares y sacerdotes en las minorías ilustradas de las que se nutre el conocimiento decimonónico era una constante en España desde el siglo XVIII. A estas dos instituciones específicas se añadían otras inherentes a su categoría de capital de provincia como el Instituto de Segunda Enseñanza, la Diputación y la Audiencia provinciales; además de las diferentes instituciones privada -casinos, periódicos, agrupaciones políticas provinciales- y la presencia de miembros de las profesiones liberales. El resultado fue que, a principios del siglo $\mathrm{XX}$, Toledo contaba con un número apreciable de potenciales interesados en las actividades eruditas propias de las clases burguesas de la época de la Restauración.

Finalmente, las propias características de Toledo -su monumentalidad, su pasado histórico, su categoría de antigua capital del reino- favorecieron desde muy temprano la aparición de una corriente anticuaria dedicada a ensalzar las viejas glorias de la ciudad, y que trajo también una relativa sensibilización hacia la protección de su patrimonio histórico y una preocupación creciente por temas tan novedosos como la gestión turística de la ciudad (Camarasa 1927). La confluencia de todas estas variables había favorecido una dinámica de creación de asociaciones, iniciativas y propuestas de investigación poco común en el interior peninsular, que en el caso de la Arqueología se plasmó 
en una fecha tan temprana como 1883 en la aparición de la Sociedad Arqueológica de Toledo (Muñoz 2002), dentro de la más estricta tradición erudita. Desaparecida en 1886 por sus roces con la Comisión Provincial de Monumentos (Ibíd.: 276), fue revitalizada en 1899 con unos parámetros muy similares. Esta segunda sociedad se mostró muy activa en sus dos primeros años de vida, tanto en la realización de excavaciones como en la publicación de su boletín bimensual, decayendo notablemente a partir de 1901 y desapareciendo en 1903 debido a problemas personales y algunos escándalos que dañaron su imagen social (Díaz 2002: 286-7).

Tras estas iniciativas efímeras el interés por la Arqueología sufrió un retroceso en Toledo -exceptuando la excavación del Cerro del Bú realizada por Manuel Castaños y Montijano-, hasta que a partir de 1910 resurgió el interés arqueológico por Toledo de la mano de las nuevas instituciones creadas por la Junta de Ampliación de Estudios. Es el caso del seminario de Estudios Semíticos del Centro de Estudios Históricos a cargo de Abraham S. Yahuda (López Sánchez 1999: 678), o del trabajo de geólogos y prehistoriadores como Hernández-Pacheco, vinculados a la Comisión de Investigaciones Paleontológicas y Prehistóricas.

Toledo ofrecía por tanto en 1919 unas condiciones interesantes para un perfil como el de Ismael del Pan, y desde su llegada se aprecia la determinación de aprovechar al máximo las posibilidades de su nuevo destino. Los años que pasa en Toledo son probablemente los de actividad académica más intensa y los de mayor implicación en las diferentes sociedades eruditas y científicas, tanto en Madrid como en Toledo. Para la ciudad, la llegada de Ismael del Pan supuso la presencia, por primera vez, de un prehistoriador profesional en el sentido amplio en que se entendía la profesión en ese momento procedente de la primera hornada de investigadores surgidos al amparo de la JAE. Esta formación en Ciencias Naturales y Prehistoria hizo de Ismael del Pan una rara avis dentro de la conservadora, provinciana $-\mathrm{y}$ en muchos casos diletante- sociedad erudita toledana y motivó que pese a su inagotable actividad docente e investigadora, la mayoría de sus iniciativas fuesen estrictamente personales y careciesen de continuidad. También, como veremos, esta falta de entendimiento científico tuvo su traslación al campo ideológico-político, donde la posición de Ismael del Pan fue aún más solitaria.
En los primeros años de su estancia en Toledo se aprecia un claro interés por colaborar con instituciones afincadas en Madrid, especialmente con la Sociedad Española de Historia Natural, la Sociedad Española de Antropología, Etnografía y Prehistoria, de las que era socio numerario, y en menor medida de la Real Academia de la Historia, de la que era miembro correspondiente. Sus publicaciones, a menudo relacionadas con actividades docentes del Instituto, siguen la tendencia iniciada en la década anterior y constituyen un buen ejemplo de la indefinición de la disciplina prehistórica en su etapa de formación. Así, encontramos trabajos sobre geología y paleontología (Pan 1921b, 1926 1923a, 1923b, 1923c, 1924, 1925a y 1925b), botánica (Pan 1921a), arqueología (Pan 1920, 1922a, 1922e y 1926b) y etnografía (Pan 1922b, 1922c, 1922d, 1926b).

Gracias a su actividad investigadora se localizó el yacimiento de La Alberquilla (Pan 1922e), situado cerca de la estación de ferrocarril de Toledo en el que pese a que por la escasez de medios tan sólo pudo llevarse a cabo una limpieza de los perfiles y el análisis de los materiales recogidos en estos y en superficie. Aunque la descripción de los resultados es breve incluye un croquis de la localización del yacimiento, un corte arqueológico-estratigráfico y dibujos de varias de las piezas. En este yacimiento del Pan identifica tres fases a las que asigna cronologías prehistórica, protohistórica y romana, aunque a través del texto es muy perceptible la indefinición existente a la hora de asignar determinadas cerámicas a un periodo cultural concreto. En el caso de La Alberquilla, clasifica la cerámica a mano de buena calidad como hallsttatiana (sic) y la de mala calidad como neolítica, identifica correctamente la cerámica ibérica a la que relaciona con la localizada en yacimientos como Castellar de Santisteban, Llano de la Consolación o Luzaga (Pan, 1922e: 144-145). Es interesante que en un momento en el que la indefinición en la identificación correcta de los materiales es la norma, Ismael del Pan consigue diferenciar correctamente las cerámicas ibéricas de aquellas de época romana pero de tradición ibérica (Pan, 1922e:146) a través de paralelos con las cerámicas romanas de Numancia. El estudio de los materiales se completa con una breve descripción de la fauna localizada - donde demuestra sus conocimientos de Historia Natural identificando las especies representadas en el yacimiento- y del único resto humano apareci- 
do, una mandíbula que el autor asocia a un individuo juvenil de pequeña talla.

La Alberquilla y la publicación de otros hallazgos aislados en la región (Pan 1920) (Fig. 2), pese a ser tan sólo apuntes breves sobre restos descontextualizados, constituyen los primeros datos procesados y presentados de manera sistemática sobre la protohistoria de la región. Asimismo y a través de las excursiones con sus alumnos a los Montes de Toledo fue uno de los primeros en aportar información sobre esta región toledana. Es el caso de las tumbas antropomorfas excavadas en la roca de Ventas con Peña Aguilera (Pan 1926b), que atribuye de manera equivocada a la Edad del Hierro, en una confusión muy común en la época. Asimismo se plantea la existencia de un posible fenómeno de megalitismo en la región, aunque en este caso las dudas son mayores y él mismo admite las dificultades para dar una interpretación satisfactoria a un conjunto de piedras graníticas con restos evidentes de manipulación antrópica pero sin función clara (Pan 1926b: 45-6). Finalmente, es interesante destacar su compromiso con las instituciones que de manera incipiente trataban de proteger y estudiar el patrimonio arqueológico de la provincia. Como miembro de la Comisión de Antigüedades de Toledo, realizó repetidas notificaciones y entregas de hallazgos a la Real Academia de la Historia (legajo CATO/9/7977/153(1) y 154), donde está documentada la entrega de los objetos recogidos en La Alberquilla y de datos sobre sus excursiones a Ventas con Peña Aguilera.

En estos artículos, Ismael del Pan deja entrever el proceso de transición entre las tendencias eruditas predominantes en ese momento y un tipo de trabajos más profundos en los que aumenta el rigor descriptivo y se hace ineludible la búsqueda de paralelos arqueológicos o etnográficos y el dominio de las últimas publicaciones especializadas. En ocasiones parece como si buscase demostrar al lec-
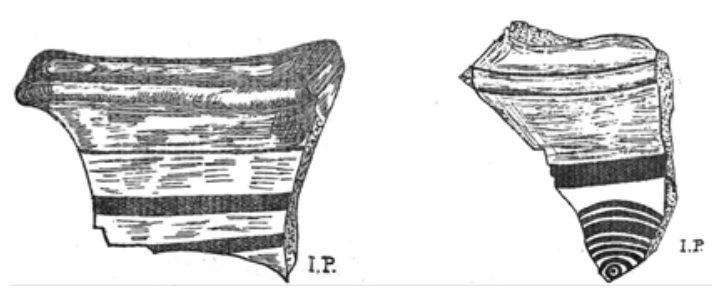

Figura 2.- Cerámicas de tipo ibérico recogidos por Ismael del Pan en los alrededores de Toledo a comienzos de los años 20 (Pan 1920, figs. 16 y 17). tor su dominio de estos elementos que denotan una forma más "científica" de investigar, frente a otros escritos eruditos, mucho más "literarios". A veces se aprecia incluso cierta tendencia a una desproporción entre la importancia del tema tratado -a menudo, simples noticias de hallazgos- y las digresiones posteriores del autor, no siempre relacionadas directamente con el objetivo principal de la publicación. Es el caso de artículos como el que reseña la primera aparición de restos protohistóricos en los alrededores de Toledo, donde pese a que se observa un rigor científico superior al habitual en este tipo de trabajos, el recurso a la bibliografía extranjera (sólo dos de las doce citas bibliográficas corresponden a autores españoles) y la recopilación de paralelos europeos parecen obedecer, dada la exigua muestra (tres objetos), más a un deseo de mostrar amplitud de conocimientos que a una utilidad real de contextualización. Del mismo modo, al tratar los materiales de La Alberquilla ocho de las once citas pertenecen a autores extranjeros.

En cuanto a su orientación interpretativa, esta se encuadra como es lógico dentro de la corriente histórico-cultural imperante en ese momento, aunque dado el tipo de trabajos que publica en estos años, esta postura teórica no es siempre explicitada. En líneas generales, las publicaciones de Ismael del Pan en estos años van a adolecer de una excesiva dispersión, poca profundidad y falta de continuidad científica, estando normalmente asociadas a paseos por los alrededores de Toledo o a excursiones con los alumnos del instituto. En realidad, su investigación al menos en la primera mitad de los años 20 puede calificarse de anárquica, debida más a la localización espontánea de hallazgos o yacimientos que a un plan de investigación definido. La impresión que produce su actividad en ese momento es la de una búsqueda de la cantidad por encima de la calidad, quizá pretendiendo aumentar sus méritos de cara a una plaza en la universidad a la que, según los datos de que disponemos, nunca llegó a optar.

En cuanto a su actividad docente, ya hemos visto de forma muy explícita cómo Ismael del Pan huía de la figura tradicional de profesor de Secundaria. Durante sus años en Toledo su principal foco de interés fue la mejora de las infraestructuras con que contaba el centro. En este sentido, su energía pronto chocó con dos obstáculos: la escasez de medios del instituto y la actitud poco comprensiva del resto del claustro hacia un profesor 
joven y brillante pero de ideas consideradas en ocasiones poco ortodoxas. El choque no sólo fue administrativo, sino también ideológico. La formación de un prehistoriador a principios del siglo XX implicaba la asunción de determinadas premisas -como el origen evolutivo de la humanidad o el rechazo al creacionismo- que colocaban a estos investigadores en una posición científica más avanzada que otros colectivos relacionados. A menudo, esta postura se correspondía también con posiciones políticas y sociales progresistas, o al menos liberales. Por los pocos datos de que disponemos para ese momento, Ismael del Pan era, ante todo, una persona de mentalidad progresista sin poder ser clasificada como "de izquierdas", y que quizá podríamos caracterizar como monárquico demócrata. Otros de sus rasgos intelectuales eran una enorme honestidad y unas fuertes convicciones personales, que le llevarían a defender posiciones que consideraba correctas independientemente del apoyo que obtuvieran, como pudo observarse a lo largo de sus años en Toledo.

Con todo, Ismael del Pan consiguió algunos de sus objetivos docentes y no dejó de pelear por otros, dedicando tiempo y esfuerzos a mejorar las instalaciones y colecciones del centro. Emprendió la ordenación y clasificación de la colección de mármoles recopilada por el cardenal Lorenzana en el siglo XVIII, completamente abandonada hasta entonces (Pan 1926a). También estudió colecciones de fósiles y de Historia Natural existentes en el instituto, publicadas en el Boletín de la Sociedad Española de Historia Natural (Pan 1925b) y en la memoria del curso académico de 1925/26 (García 1999: 209). Gracias a sus esfuerzos aumentaron las donaciones de fósiles y minerales, se mejoró y expandió el Jardín Botánico creado por Luis de Hoyos Sáinz y se solicitó repetidamente la mejora del laboratorio del instituto (García 1999:209). En cuanto al enfoque que otorgaba a sus clases, las continuas salidas al campo con sus alumnos muestran un profesor muy activo y preocupado por la enseñanza práctica de sus asignaturas. No parece, ni por su trayectoria personal ni por los datos de que disponemos, que Ismael del Pan formara parte a la Institución Libre de Enseñanza, aunque algunos de sus métodos de trabajo y en particular la importancia que prestaba a la labor investigadora y práctica le acercaban a algunos de sus presupuestos.

A partir de la segunda mitad de la década de los años veinte se observan cambios apreciables en la situación académica, personal y científica de Ismael del Pan. En el primer aspecto, los libros de actas del instituto de Toledo muestran un progresivo aislamiento en el claustro, donde tiene frecuentes enfrentamientos por asuntos relativos a la dirección del centro, que en ocasiones presentan un marcado carácter ideológico, recibiendo siempre un apoyo mínimo. Así, en 1927 mantiene un duro y larguísimo enfrentamiento con otros claustrales respecto de la democratización de la Junta Económica que gestiona el presupuesto, y en ese mismo año vuelve a oponerse a la declaración de apoyo al golpe de estado de Primo de Rivera (García 1999: 211).

Este aislamiento se verá contrarrestado por una creciente relación de Ismael del Pan con los miembros de la Real Academia de Bellas Artes y Ciencias Históricas de Toledo (RABACHTO). Fundada en 1916, esta institución recoge el ideario y el espíritu de las dos sociedades arqueológicas previas, de forma más coherente y con objetivos más amplios. Organizada inicialmente en tres secciones (Ciencias Históricas, Artes liberales y Artes Industriales), adquirió pronto prestigio y estabilidad, pero su enfoque siguió siendo el de una asociación erudita al uso de las sociedades del siglo XIX, alejándose de las nuevas tendencias científicas que en estos momentos comenzaban a extenderse desde Madrid. Pese a esta postura conservadora, será a través de esta institución donde a partir de 1927 Ismael del Pan va a poder canalizar sus inquietudes investigadoras.

Éstas van a sufrir además cambios sustanciales en este periodo, apreciándose un claro aumento de interés hacia los estudios etnológicos y especialmente el mundo de las supersticiones, prácticas mágicas y creencias religiosas, tema que había tratado ocasionalmente pero que ahora comienza a ocupar un lugar central dentro de su investigación (Pan 1927, 1928, 1929). El mismo año de su admisión en la RABACHTO ya plantea la apertura de una sección de Folclore, y a partir de este momento la presencia de Ismael del Pan se hace permanente en la primera institución que apoya decididamente sus iniciativas. En este sentido, ya desde 1927 y hasta su partida de Toledo ocupa el puesto de secretario, redactando las correspondientes memorias de los años académicos (Pan 1930b, 1930c, 1930d). Sin embargo, sus esfuerzos se centran en la organización de la mencionada sección de Folclore, para lo que aprovechó la red de con- 
tactos e informadores creada durante sus salidas al campo. Además de la suscripción a revistas de etnología, se propone el que quizá fuese su proyecto más ambicioso: la creación de un Archivo de Folclore Toledano para el que se preparó un cuestionario etnológico exhaustivo y que se completaría con una colección de folclore de la provincia de Toledo anunciada en la memoria del curso 1930/1931.

Por supuesto, esta creciente dedicación a la Etnología no impidió que, como uno de los arqueólogos más expertos de la ciudad, participara en aquellas actividades relacionadas con este ámbito que se desarrollaron en la provincia. La RABACHTO cumplía en parte el papel de protectora del patrimonio de la ciudad y la provincia, y siguiendo ese espíritu Del Pan participó activamente en la discusión sobre los hallazgos prehistóricos de La Guardia (Pan 1930a), donde se realizó una visita para comprobar la existencia de restos arqueológicos en las cercanías de un cerro de la localidad tras la cual se concluyó que el supuesto yacimiento había sido destruido por expoliadores. La memoria redactada para informar a la RABACHTO es interesante tanto por mostrar la preocupación de los ponentes por la destrucción del patrimonio arqueológico como por algunas de las interpretaciones que realizan sobre los modos de vida de las poblaciones neolíticas que asocian al cerro. Es especialmente significativa por su modernidad una reflexión acerca del comercio de larga distancia necesario para que las piedras de diorita o fibrolita recogidas en el cerro hayan llegado hasta allí, utilizando conceptos como el de productos de importación (Pan, 1930: 101).

Asimismo, Ismael del Pan estará presente en las excavaciones que se realizaron a finales de los años treinta en el circo romano de Toledo (Castaños et al. 1928; San Román et al. 1930), publicadas dentro de las Memorias de la Junta Superior de Excavaciones Arqueológicas en lo que constituye el proyecto arqueológico de mayor entidad en el que participó. Estas excavaciones pretendían delimitar y recuperar los restos del circo situado en la zona de la Vega Baja. Estos restos habían sido objeto de varios estudios parciales (Castaños et al. 1928: 5), pero hasta 1927 no se emprendió un plan sistemático para tratar de localizar las diferentes estructuras (perímetro, carceres, spina) y, aprovechando los conocimientos de topografía de Alfonso Rey Pastor, trazar un plano del edificio.
Las excavaciones se desarrollaron durante tres años con presupuestos escasos y aunque las memorias son bastante escuetas, de ellas proviene la mayor parte de la información de que disponemos para la reconstrucción de la planta del circo. De la precariedad con que se desarrollaron los trabajos da cuenta el hecho de que las excavaciones persiguieran tan sólo tomar datos para completar las planimetrías, siendo los restos cubiertos de nuevo incluso en los casos en que éstos se encontraran en terrenos municipales (San Román et al. 1930: 10).

En muchos aspectos, los años de colaboración con la RABACHTO marcan el momento en que Ismael del Pan se asienta como investigador, dentro de una institución que le ofrece una plataforma desde la que desarrollar sus iniciativas científicas, una revista donde publicar los resultados y, sobre todo, una línea de investigación definida que corrigiera su tendencia a la dispersión. Se observa entonces un interés menor por colaborar con instituciones madrileñas, bien por haberse desengañado de sus posibilidades para acceder a un puesto en la Universidad, bien porque se sentía satisfecho con su situación actual. Por desgracia, a partir de la proclamación de la Segunda República en 1931 su situación en el instituto de Toledo sufrirá un dramático cambio como consecuencia de sus posiciones políticas que afectará de manera definitiva a su carrera académica y a su vida personal.

La llegada de la República y su actividad legislativa tuvo evidentes consecuencias en la vida de los institutos. En el caso del de Toledo, donde el espíritu era especialmente conservador, las nuevas medidas impuestas desde el gobierno fueron rechazadas o desvirtuadas, especialmente la relativa a la elección de un nuevo director del centro. Frente a una abrumadora mayoría de claustrales, Ismael del Pan defendió en una reunión muy tensa la necesidad de renovar no sólo este puesto sino el conjunto de la vida pública y administrativa de la ciudad y el país, haciendo gala de un fuerte talante democrático y de compromiso social y ético, y asumiendo en gran medida los valores del nuevo gobierno (Ruiz 2005: 57) pese a que, como hemos dicho, no era republicano (años después, en su expediente de depuración, se definirá como monárquico). Completamente solo y ante la reelección del antiguo director del centro, Ismael del Pan abandonó la reunión y en un acto que podría considerarse de rebelión ética solicitó su traslado a otro instituto. Tras optar a una vacante en Bilbao, consiguió plaza 
en el Instituto Balmes de Barcelona, al que se incorporó en el curso 1931/1932.

Podría alegarse que el desencuentro de Ismael del Pan con el resto del centro en el que trabajaba venía de largo, y por tanto su solicitud de traslado quizás fuese premeditada. Si atendemos a los diversos proyectos que dejó pendientes en la RABACHTO, como el cuestionario etnográfico y la publicación de la colección de Folclore Toledano, cuya primera entrega estaba a punto de imprimirse, la decisión parece más bien espontánea y con un planteamiento ideológico, que buscaba mostrar su rechazo al conservadurismo de sus compañeros y a su actitud intelectual aburguesada y conformista. En cualquier caso, la partida de Ismael del Pan privó a Toledo de uno de sus profesores más activos, con un perfil científico y pedagógico avanzado y un fuerte compromiso institucional y social con la ciudad.

Pese a estos méritos y a su reconocida valía como profesor e investigador, la huella que Ismael del Pan dejó en Toledo fue escasa. Su dispersión inicial y sus características personales (formación, intereses, etc.) hacían de él una personalidad única en el mundo científico y literario de la ciudad, y era difícil que otros investigadores continuaran su trabajo. El resto de miembros de la RABACHTO pertenecían a la corriente anticuarista predominante en la ciudad y en la mayor parte del país, sus intereses apuntaban hacia la Arqueología clásica o la Historia de Arte. Es el caso de Alfonso Rey Pastor (militar y geógrafo), Manuel Castaños Montijano (militar, presidente de la Comisión Provincial de Monumentos), Pedro Román Martínez (pintor y profesor de la Escuela de Artes y oficios artísticos) o Juan Moraleda y Esteban (médico, fundador de la segunda Sociedad Arqueológica de Toledo). Estos investigadores, que componían el núcleo duro de los especialistas en arqueología, estaban centrados principalmente en el mundo romano y en un concepto de arqueología decimonónico, con intereses y formación muy alejados de la Etnografía o Arqueología prehistórica.

El resultado de esta divergencia de intereses se plasmó en la escasa vida de la sección de Folklore de la RABACHTO y otras iniciativas de corte etnográfico, que no sobrevivieron a la partida de Ismael del Pan en 1931. La actividad de éste en Toledo evidencia cómo pese a la profunda renovación desarrollada durante los treinta años anterio- res y al aumento de las infraestructuras investigadoras en todo el país, el grueso de la comunidad científica-especialmente en las provincias- trabajaba todavía dentro de parámetros muy conservadores. Además muestra de manera muy explícita cómo los cambios desarrollados en el ámbito científico tenían en gran medida correlaciones ideológicas y en muchos casos políticas, y cómo los investigadores con formación científica más avanzada chocaban a menudo académica e ideológicamente con el resto de la comunidad, y en la práctica constituían una minoría casi dramática fuera de las grandes ciudades. Aunque el debate entre ideología política y una actividad como la arqueología escapa a los objetivos de este artículo, acabamos de ver cómo el resto de arqueólogos que trabajaron junto a Ismael del Pan en Toledo pertenecían bien a instituciones como el Ejército, bien a las filas de la burguesía provincial heredera de la Restauración, y en ambos grupos es evidente el predominio de un tipo de pensamiento conservador. Otros datos como las concesiones de permisos para excavaciones de la Junta Superior de Excavaciones y Antigüedades y la posterior Junta Superior del Tesoro Artístico apuntan también en esa dirección (Díaz-Andreu 1997: 408-9).

En el aspecto personal, Ismael del Pan aparece como un ejemplo perfecto de este choque entre dos maneras de entender la ciencia, tanto en los aspectos estrictamente académicos como en sus prolongaciones educativa, social e incluso moral. Su identificación con los objetivos educativos y democratizadores de la República no se hizo desde una posición política partidista, sino desde la continuidad del pensamiento regeneracionista en el que se educó y probablemente desde su propia perspectiva de alumno sin recursos que estudió gracias a becas municipales. También es necesario reconocer su honestidad al defender en solitario en dos ocasiones la legalidad democrática frente al conformismo o la rebeldía de la mayoría. Los años siguientes, por desgracia, pondrán a prueba esta honestidad en algunas situaciones realmente dramáticas.

\section{Años difíciles: Barcelona y Albacete}

Para reconstruir la actividad de Ismael del Pan durante los años de la República contamos con dos fuentes principales de información: la referente a 
su pensionado por la Junta de Ampliación de Estudios en el extranjero en 1935 y los datos obtenidos a través del análisis de su expediente de depuración tras la Guerra Civil, además de información complementaria procedente de sus publicaciones en este periodo. Aunque los datos son más escasos que en etapas anteriores, sabemos que Ismael del Pan se incorporó al Instituto de Balmes en Barcelona en el curso de 1932/1933. Lo hizo como un catedrático e investigador respetado, y en un primer momento parece que trató de continuar sus líneas de trabajo iniciadas en Toledo. Así, en 1932 se publica el primer y único tomo de la colección de Folklore Toledano (Pan 1932) que probablemente había dejado terminado antes de salir de Toledo, y sabemos que fue declarado miembro correspondiente de la RABACHTO en Barcelona. Parece que en los años siguientes se dedicó exclusivamente a la docencia, publicando un manual de Ciencias Naturales (Pan 1934) (Fig. 3), aunque no abandonó su interés por la Etnología y en 1934 viajó a Portugal durante un mes para estudiar aspectos del Folklore de este país (Archivo de la JAE, expediente 110-71).

En enero de 1935 dio un paso más y solicitó una pensión en el extranjero a la JAE, siendo probablemente uno de los investigadores más veteranos en acogerse a este programa. El objetivo de su proyecto investigador continúa la línea de trabajo por la que había comenzado a interesarse en Toledo, planteando realizar "un estudio comparado de aquellos materiales del Folclore material y espiritual, que, en países limítrofes al nuestro, como Portugal y Francia, poseen colecciones y museos etnológicos de importancia (...)" (Archivo de la JAE, expediente 110-71). Ismael del Pan solicitó una estancia de tres meses para estudiar las colecciones de los Museos de Lisboa, Coimbra y París. Como posibles mentores en su trabajo citaba a René Verneau en Francia y Vergilio Carreira y Alberto Vieira en Portugal.

La pensión le fue concedida, pero la tardía resolución de la concesión de las pensiones y las obligaciones docentes del pensionado limitaron seriamente el proyecto previsto, como el propio autor expresa en el resumen que entrega en septiembre de 1935 (Archivo de la JAE, expediente 110-71). En éste se recoge cómo la pensión se redujo a un mes y medio y se limitó a Portugal, donde estudió las colecciones del Museo Etnológico de la Sociedad de Geografía de Lisboa, el Museo "Leite de

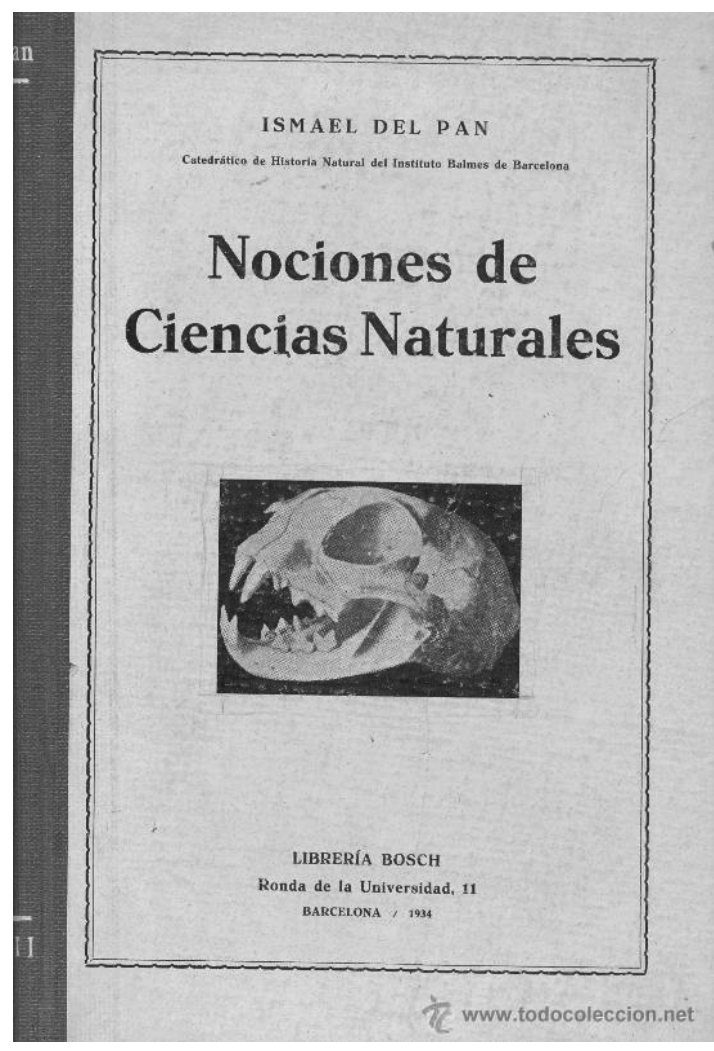

Figura 3.- Portada del libro de Ismael del Pan publicado en 1934 (Foto: www.todocoleccion.net).

Vasconcellos" de etnología portuguesa, el Servicio Geológico de Portugal y el Museo de la Academia de Ciencias y donde estuvo en contacto con un relevante número de etnólogos y arqueólogos portugueses, incluyendo a Leite de Vasconcellos, Santos Junior y Alberto Vieira. Su estudio se completó con recopilación de bibliografía y trabajo de campo en la zona entre los ríos Sado y Duero.

A su vuelta a Barcelona en el otoño de 1935, Ismael del Pan había recopilado una considerable información, pero la necesidad de organizar el trabajo y preparar láminas para los numerosos dibujos que había realizado durante su estancia hizo que hasta finales de abril de 1936 no pudiese presentar la memoria de trabajo, en la que planteaba la posibilidad de publicar el trabajo a través de la JAE si ésta lo estimaba conveniente (Archivo de la JAE, expediente 110-71). Tras varias consultas se recomendó la publicación de la memoria, pero la mala suerte le jugó una mala pasada a Ismael del Pan. Desconocemos cuál hubiese sido la decisión última de la Comisión de Publicaciones - probablemente favorable- pero en cualquier caso la suble- 
vación militar de julio de 1936 acabó con cualquier posibilidad de llevar a buen término este proyecto, que no vería la luz hasta siete años después.

El gobierno republicano en Cataluña durante la Guerra Civil debió de suponer para Ismael del Pan una amarga experiencia. Rechazado en Toledo por defender las propuestas de regeneración democrática que defendía la República, en Barcelona su postura moderada y monárquica le enfrentó pronto a las posiciones nacionalistas y socialistas más radicales. En una de las preguntas del expediente de depuración en la que se le exige declarar cuanto sepa sobre este periodo, Ismael del Pan muestra claramente su desagrado con los mecanismos de control político sobre el sistema de enseñanza, el peso de la posición ideológica a la hora de acceder a cargos públicos y el nacionalismo de algunos sectores del gobierno republicano en Cataluña. $\mathrm{Su}$ postura parece haber sido muy similar a la demostrada en Toledo, defendiendo los valores de la enseñanza por encima de situaciones políticas y con un enfoque educativo progresista que no estaba reñido con una postura conservadora moderada. Como en su momento en Toledo, tampoco parece que rehuyera expresar su opinión incluso en las situaciones más complicadas. Su defensa de estas posiciones debió ser tan enérgica que pese a ser en esos momentos el vicedirector del Instituto de Balmes, menos de un año después de iniciada la guerra se le sancionó con un traslado a Albacete, adonde llegó el 4 de marzo de 1937. En su expediente se cita como principales artífices de su depuración al Comisario-Director del Instituto, Rafael Candel Vila, a un ayudante llamado Ambrosio Carrión y a un secretario apellidado Blasco, que le delató como monárquico (AGA legajo 18523, expediente 52). Según su versión, estas personas estaban apoyadas por el rector del Patronato Universitario, Pedro Bosch Gimpera.

Tal y como dijimos más arriba, el traslado a un instituto menor como el de Albacete suponía no sólo una sanción administrativa, sino también una pérdida del prestigio adquirido en los años previos. En Albacete pasaría el resto de la guerra, hasta que la victoria del bando sublevado le enfrentó a uno de los procesos más siniestros del régimen franquista: el expediente de depuración. El caso de Ismael del Pan es un ejemplo muy claro del creciente desencuentro que sufrieron muchos de los sectores de ideología conservadora moderada con los sucesivos gobiernos de la Segunda República.
Pese a todo y como veremos más adelante, el enfrentamiento de Ismael del Pan con las instituciones republicanas se centró esencialmente en aspectos relativos a la gestión del centro de enseñanza (especialmente, al control de los comisariosdirectores) y en el nacionalismo catalán de parte del gobierno de la Generalidad, antes que en el fondo de muchos de los valores que la República había tratado de defender.

\section{Depuración}

Mucho menos explícitos que los fusilamientos, la cárcel o los campos de trabajos forzados, los expedientes de depuración constituyen un ejemplo más invisible pero no menos siniestro de la represión franquista en los años posteriores a la guerra. En el caso de los profesores de instituto y de educación primaria, decenas de miles fueron depurados y muchos de ellos apartados de por vida de sus puestos de trabajo, en lo que constituye la mayor desmembración del tejido educativo en la historia de nuestro país, tanto más triste por cuanto fue realizada de manera intencionada. Más que en las grandes figuras de la cultura o la ciencia españolas que tuvieron que exiliarse o que sufrieron un dramático final, es en esta silenciosa evaluación y en muchos casos sanción donde reside la verdadera tragedia del retroceso experimentado por la educación y la investigación españolas a partir de los años cuarenta.

Generalmente se habla de los expedientes de depuración de manera genérica, indicando su existencia o resultados, pero pocas veces se ha analizado cuáles eran los mecanismos de evaluación y cómo se afrontaban unas respuestas que evidentemente buscaban satisfacer los criterios impuestos desde la autoridad. Su forma física era un cuestionario en el que se buscaba valorar la actividad del individuo depurado antes de la guerra, su adhesión o no al régimen, su participación -y en qué bandoen la guerra y qué esfuerzos hizo para apoyar al bando "nacional" durante la misma. Se solicitaba el aval escrito de al menos dos personas que confirmaran la declaración del depurado, además de documentación en muchos casos difícil o imposible de conseguir en la situación en que se encontraba el país tras el conflicto. La última pregunta era especialmente siniestra en tanto que constituye una exigencia de delación en toda regla: "Indique cuan- 
to sepa del periodo revolucionario, principalmente en lo relacionado con el desenvolvimiento público y administrativo del Ministerio e indique asimismo la actuación que conozca de sus compañeros".

La posición de Ismael del Pan es interesante porque probablemente representa la situación más común en estos expedientes: la de personas que no se habían involucrado directamente en la guerra, de posiciones moderadas que se habían visto superadas por un conflicto que no deseaban y obligadas a firmar un documento con el que no estaban de acuerdo pero que era indispensable para poder continuar con su trabajo y vida dentro de una mínima normalidad. Las respuestas de Ismael del Pan ejemplifican muy bien esta posición, y muestran una mezcla de parquedad, respuestas estándar y situaciones que mezclan problemas personales con las imposiciones del cuestionario.

Es justo reconocer que Ismael del Pan partía de una situación ventajosa: su excedencia forzosa del Instituto Balmes y su traslado disciplinario a Albacete hacían de él una persona perjudicada por la República y por tanto que no debería tener problemas para "recolocarse" en su puesto. Sin embargo, las respuestas de Ismael del Pan (AGA legajo 18523, expediente 52) no traslucen un excesivo entusiasmo con el nuevo régimen. Son escuetas y en algunos casos parecen frases hechas usando terminología muy forzada -terror rojo, separatismo, etc.-, en lo que parece más un intento de complacer a los tribunales de depuración que una posición ideológica firme. Tan sólo en un aspecto -el de su traslado a Albacete-, evidencia su rencor hacia las instituciones republicanas, citando como hemos dicho a varios de los que considera culpables de su caída en desgracia en Barcelona. Durante los meses de abril a agosto de 1939, Ismael del Pan recoge los avales que confirman su posición "favorable" al gobierno franquista, entre ellos los de los directores de Albacete y Barcelona, pero se topa con un obstáculo inesperado ya que se le exige una hoja adicional en la que informe de nuevo sobre el comportamiento de sus compañeros, en este caso del instituto de Albacete. En este caso, la respuesta de Ismael del Pan nos parece un ejemplo de honestidad personal -no había lugar a la heroicidad- en una situación dramática en la que estaba en juego su futuro profesional. Incluimos aquí, por su indudable interés, una parte de su contestación:

Complutum, 2011, Vol. 22 (1): 27-46
"Debo manifestar que no tengo conocimiento de que durante el periodo rojo se hayan cometido actos delictivos, transgresiones de orden moral ni profesional, faltas en el cumplimiento del deber, arbitrariedades o abusos en el Instituto Nacional de Segunda Enseñanza de Albacete, por aquellas personas que ejercieron cargos directivos en el mismo, ni por el profesorado que desempeñaba cátedras y servicios docentes.

Como personas destacadas por su política de izquierdas, pertenecientes al profesorado del mencionado Instituto de Albacete, figuraban el Ayudante de la Sección de Ciencias, D. Enrique Navarro, y los catedráticos D. Pedro Casciaro y D. Rafael Selfa. Los dos primeros desempeñaban el cargo de Comisario Director del Instituto, realizando personalmente, en conferencias y actos públicos la labor de propaganda en que por su ideario político u obedeciendo órdenes superiores se creyeron obligados, sin que en ningún caso, ni por ningún concepto, nos obligaran a tomar parte en tales actos a los compañeros de profesorado que no participábamos de sus sentimientos e ideas a quienes nos distinguieron con el homenaje del respeto de nuestras conciencias (sic).

El catedrático de Filosofía, D. Rafael Selfa, participó, asimismo, en conferencias y actos de propaganda de la F.U.E. en materias docentes; pero sin estridencias, y en su trato social, como compañero, dispensábamos (sic) cordialidad y camaradería a quienes permanecíamos distanciados de su conducta política.

De los tres señores mencionados, D. Enrique Navarro, Diputado de Cortes de Izquierda Republicana y Director General de Obras Hidráulicas, huyó al extranjero antes de liberarse Barcelona por el Ejército Nacional; D Pedro Casciaro huyó asimismo en vísperas de liberar Albacete y D. Rafael Selfa sufre actualmente prisión por haber sido detenido en Albacete al entrar en dicha ciudad las tropas nacionales (...)".

Con todas sus miserias y dudas, el expediente de Ismael del Pan transmite una enorme sensación de humanidad al mostrar por una parte el miedo y la necesidad de doblegarse para conservar su trabajo y por otra su rebelión interna ante el sinsentido de la depuración y las delaciones exigidas. El resultado del expediente fue, como cabía esperar, positivo, e Ismael del Pan fue confirmado en su puesto en el Instituto Balmes. Sin embargo, parece que no acabó nunca de encontrarse cómodo en Barcelona, 
y el 2 de abril de 1941 se le concedió el traslado al Instituto Lope de Vega en Madrid (AGA, MEC, Caja 97-241).

\section{Conclusión en Madrid}

Ismael del Pan se incorporó a su nuevo instituto con 50 años $\mathrm{y}$, haciendo gala de la energía que desarrolló durante toda su vida, siguió investigando en la medida de sus posibilidades, centrándose definitivamente en los estudios etnográficos. En Madrid va a seguir vinculado a la Real Sociedad Española de Historia Natural, de la que será presidente en 1950 y en la que publicó ocasionalmente (Pan 1942, 1946a, 1946c, 1946b, 1948c, 1949a, 1949d, 1950b, 1954, 1959), generalmente pequeñas notas o reseñas. También mantendrá su colaboración con la Sociedad Española de Antropología, Etnografía y Prehistoria, a través de la que verá la luz el manuscrito de su pensionado en Portugal (Pan 1943). Este libro de más de doscientas páginas constituye la obra de mayor entidad publicada por Ismael del Pan, conformando un monográfico anual de la revista que publicaba esta sociedad, y en ella se plasman las líneas principales de su enfoque metodológico y su estilo de investigación. Respecto del primero, se aprecia un gran interés por el contexto geográfico de las diferentes regiones estudiadas y cómo éste influye en las características sociales y espirituales (según la terminología de la época) de las poblaciones. Es interesante cómo de manera recurrente se remarca el peso de este entorno geográfico sobre demarcaciones políticas (Pan 1943: 32, 50-51, 65-66, 213) o particularismos históricos. La primera parte del trabajo describe las zonas que han sido objeto de estudio, sus característica geográfico-geológicas y aquellos elementos etnográficos que considera de interés: objetos, vestimentas, canciones tradicionales (Fig. 4).

La segunda parte del trabajo es mucho más específica y obedece al interés que desde mediados de los años 20 había demostrado el autor por el mundo de las supersticiones populares (Fig. 5). La estructura de su exposición es muy clara, tras una introducción teórica en la que diferencia el pensamiento asociativo de los pueblos primitivos del pensamiento lógico de los pueblos desarrollados, la pervivencia de supersticiones en los pueblos actuales y su plasmación física en amuletos y talis-

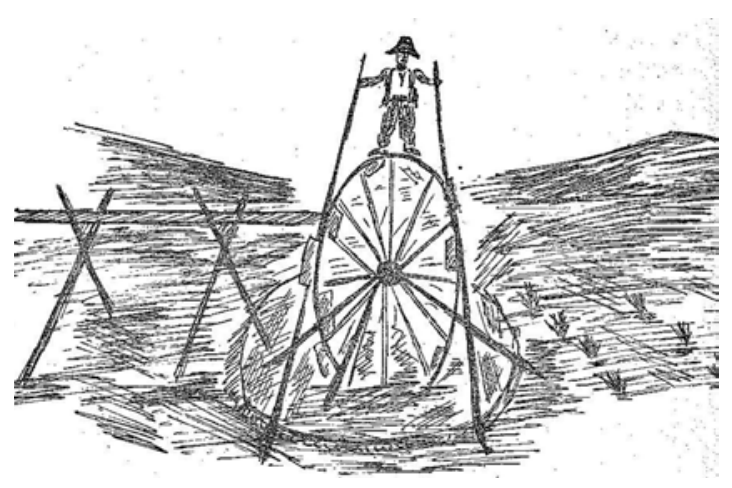

Figura 4.- Dibujo de una noria documentada por el autor durante su estancia en Portugal en 1934 (Pan 1943: fig. 21).

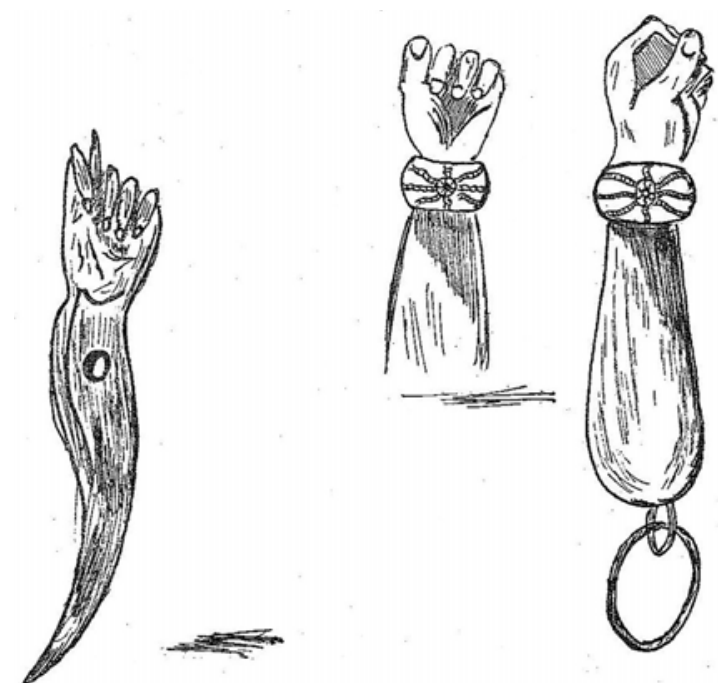

Figura 5.- Dibujos de amuletos portugueses recopilados por Ismael del Pan en su estancia en Lisboa (Pan 1943: figs. 32-33).

manes, Ismael del Pan pasa a desgranar los diferente tipos de creencias -lugares, objetos, elementos de la naturaleza como árboles o cursos de agua, animales, diferentes tipos de magia y hechizos etc.- través de ejemplos tomados de diferentes regiones de España y Portugal. El trabajo termina con una serie de conclusiones que resumen los diferentes tipos de magia -animista, animal, preservadora, etc.- documentados y su influencia en los dos países.

En el libro de Ismael del Pan pueden apreciarse algunas características que pueden definir su concepción de la Etnología, del pensamiento mágico y del lugar de las supersticiones en las sociedades rurales. Ya se ha hecho alusión al gran peso que 
otorga a la geografía y al medio ambiente en el desarrollo cultural de los pueblos -"la Geografía condiciona la Historia (Pan 1943:213)-, al que se une un fuerte principio evolucionista por el cual el progreso humano es el que hace sustituir las creencias producto del pensamiento asociativo por las basadas en el pensamiento lógico (Pan 1943:7273). La superstición es concebida así en dos variables: la espacial (al aparecer dentro de un contexto geográfico) y la temporal (como residuo de formas de pensamiento antiguas).

Las líneas de pensamiento establecidas en su principal trabajo van a continuarse durante los años siguientes, aunque desde los 40 sus estudios van a centrarse en su área natal de La Rioja, publicando asiduamente en la revista local Berceo (Pan 1946d; 1948a; 1948b; 1949b; 1949c, 1950a, 1951; 1952; 1953a, 1953b). En sus publicaciones tratará de establecer las primeras líneas de estudios sobre etnografía riojana y mostrará de nuevo una especial preocupación por el contexto geográfico de los diferentes pueblos estudiados en sus aspectos mitológicos y espirituales e independientemente de los límites políticos o administrativos (Pan 1949b; 1949c: 480). Su planificación de un proyecto de investigación etnográfica para La Rioja (Pan 1949b) muestra claramente estas preocupaciones, proponiendo las comarcas como los espacios más adecuados para el estudio etnográfico. Este interés por el contexto geográfico como criterio básico para la comprensión de la cultura entronca directamente con la obra de autores mucho más conocidos como Luis de Hoyos Sáinz, para el que Etnología y Geografía humana se encontraban íntimamente asociadas y cuyo método de análisis era antropogeográfico (Ortiz, 1987: 310-311). En este sentido, es interesante recordar que Ismael del Pan tuvo contacto personal con Luis de Hoyos en el contexto de la Sociedad Española de Antropología, Etnografía y Prehistoria, de la que ambos eran miembros.

Se observa por tanto en Ismael del Pan una concepción global de la Etnografía que abarca el estudio de todos los aspectos de la vida (económicos, sociales, estéticos, espirituales, etc.), además de la recolección de materiales y la creación de instrumentos de publicación de los datos recogidos. Asimismo, sus propuestas se alejaban del particularismo histórico al plantear estudios comparativos entre diferentes regiones geográficas, tanto entre España y Portugal (Ortiz 1994: 539) como entre La
Rioja y otras provincias limítrofes (Pan 1949b). Pese a esta perspectiva, la actividad de Ismael del Pan fue alejándose cada vez más de las líneas de investigación más novedosas, tanto por la aparición de nuevas generaciones de investigadores como por la precariedad de medios existentes en la posguerra, adaptándose al tono erudito que, salvo honrosas excepciones, caracterizó la Arqueología y la Etnografía de los años 40 y 50. Analizando el tipo de publicaciones con las que colaboró Ismael del Pan a partir de 1939, se aprecia un fuerte predominio de revistas de ámbito local o pertenecientes a instituciones formadas antes de la Guerra Civil, mientras que su relación con nuevas instituciones como el CSIC fue mucho menor, colaborando sólo de manera ocasional en publicaciones como la Revista de Dialectología y Tradiciones Populares en su primer año de existencia (Pan 1944a, 1944b). Su participación en congresos y reuniones científicas parece haber sido escasa en estos años, aunque asistió a alguno de manera esporádica como consta en su solicitud realizada en 1956 ante el claustro del instituto para asistir al Primer Congreso de Etnografía y Folklore realizado en Braga, al que había sido invitado como huésped de honor (AGA, MEC, Caja 97-241). Todos los datos -características y ámbito de sus publicaciones, repercusiones científicas de las mismas, etc.- apuntan a la progresiva recolocación de Ismael del Pan en un ámbito alejado de las dinámicas académicas creadas tras la guerra y más cercano a la figura del erudito local.

En este sentido, la ruptura de la estructura científica previa a la Guerra Civil, la pérdida de peso de muchas instituciones fundadas a finales del siglo XIX y comienzos del XX por una parte, y las dificultades en la institucionalización y consolidación de la Etnología en España a partir de las primeras décadas del siglo XX (Ortiz 1987: 286-287) por otra cerraron sus posibilidades para mantenerse en la primera línea de la investigación académica. A estos problemas pueden añadirse otros como el cambio generacional en la investigación tras la guerra-Ismael del Pan ya tenía en ese momento 50 años-e incluso simbólicos, como representante de un periodo a superar. Es interesante este cambio porque un personaje que en los años 20 formaba parte del núcleo más avanzado de la investigación prehistórica, una generación después había sido relegado a una posición erudita similar a la que él había pretendido superar. 
En cuanto a su labor docente, la información es escasa salvo algunas notas que muestran su compromiso permanente con ella. Sabemos que permaneció como catedrático emérito hasta los 70 años y que días antes de su jubilación solicitó continuar en su puesto sin sueldo hasta concluir el periodo de exámenes y la corrección de los mismos (AGA, MEC, Caja 97-241). Tras su jubilación no publicó más artículos, a excepción de una breve nota necrológica de su amigo Paul Wernert (Pan 1959) y otra de agradecimiento al homenaje que en 1964 le dedicó la RABACHTO (Pan 1964). Cuatro años después su muerte fue recogida en la Revista de Dialectología y Tradiciones Populares, donde se reconoce su aportación a los estudios de la Etnografía española (1968).

La valoración de la actividad científica y docente de Ismael del Pan debe realizarse en varios niveles. En un aspecto estrictamente científico, es evidente que su producción no llegó al nivel de otros investigadores junto a los que trabajó y que formaron la primera fila del lanzamiento de la ciencia española en las tres primeras décadas del siglo. Sin embargo, si dejamos a un lado estas personalidades y valoramos el impacto que investigadores de nivel medio como Ismael del Pan tuvieron en las instituciones educativas españolas de la época, las conclusiones son muy diferentes. Más allá de los cen- tros de primer orden, la gran lucha por romper el atraso educativo español se dirimió en los niveles de la educación primaria y secundaria, y fue en esos terrenos en los que una nueva generación de profesores peleó por implantar una forma renovada de educar en la escuela y en la sociedad.

Los frutos que esta política pudo haber producido se los llevó la tragedia que representó la Guerra Civil, y del esfuerzo y la vocación de miles de docentes e investigadores apenas nos quedan sus publicaciones y los documentos oficiales que dan fe de su trabajo. En el caso de Ismael del Pan, a estas circunstancias se unen además su honestidad personal y una humanidad que hacen aún más interesante el personaje, a la vez que las vicisitudes de su vida permiten acercarnos desde una perspectiva diferente a una etapa muy compleja de la historia de España. Ismael del Pan aprovechó al máximo las posibilidades que los cambios educativos y científicos de comienzos de siglo le ofrecieron. Sus problemas en Toledo, su actitud política y la Guerra Civil le impidieron desarrollar una carrera investigadora consistente. Si embargo, no parece que estos problemas le alejaran jamás de su verdadera pasión: la visión global de un mundo -el medio, el ser humano y su pasado- que asumió en su etapa de formación y que le acompañó el resto de su vida.

\section{REFERENCIAS BIBLIOGRÁFICAS}

Álvarez, P. (ed.) 2001: Cien años de educación en España: en torno a la creación del Ministerio de Instrucción Pública y Bellas Artes. Ministerio de Educación, Cultura y Deporte, Madrid.

Camarasa, S. (1927). Turismo. Boletín de la Real Academia de Bellas Artes y Ciencias Históricas de Toledo, 30: 328.

Castaños, M., Pan, I. Del., Román, P.; Rey, A. (1928). Excavaciones en el circo Romano de Toledo. Memorias de la Junta Superior de Excavaciones Arqueológicas, 96.

DíAz, G. (2002). Apuntes sobre la Sociedad Arqueológica de Toledo (1899-1903) y su boletín. Archivo secreto: revista cultural de Toledo, 1: 284-95.

DíAZ-ANDreU, M. (1997): Nación e internacionalización. La Arqueología en España en las tres primeras décadas del siglo XX. La Cristalización del Pasado: génesis y desarrollo del marco institucional de la arqueología en España (Díaz-Andreu, M. y Mora, G., eds.), Málaga: 403-416.

DíAZ-Andreu, M. (1997): Prehistoria y franquismo. La Cristalización del Pasado: génesis y desarrollo del marco institucional de la arqueología en España (Díaz-Andreu, M. y Mora, G., eds.), Málaga: 547-552.

Fusi, J.P. (1999): El despertar de la cultura española (1900-1931). Los significados del 98 : la sociedad española en la génesis del siglo XX (Ruiz-Manjón, O. y Langa, A., eds.) Biblioteca Nueva, Madrid: 769-775

García, F. (1999). Ciriaco Ismael del Pan Fernández. Profesor del Instituto desde 1919 a 1931. Biografias y semblanzas de profesores. Instituto "El Greco" (1845-1995). Instituto de Enseñanza Secundaria El Greco, Toledo: 203-12. 
GómEz, M.N. (2001). La enseñanza secundaria pública en España: un antes y un después de la creación del Ministerio de Instrucción Pública y Bellas Artes. En Álvarez 2001: 409-29.

Hoyos, N. de (1968). Don Ismael del Pan (1889-1968). Revista de Dialectología y Tradiciones Populares, 24(3/4): 415.

LóPEZ, J.M. (1999). El Centro de Estudios Históricos: primer ensayo de la Junta para Ampliación de Estudios en trabajos de investigación. Los significados del 98: la sociedad española en la génesis del siglo XX. (O. Ruiz-Manjón y A. Langa, eds.). Biblioteca Nueva, Madrid: 669-82.

LóPez, J.M. (2006). Heterodoxos españoles: el Centro de Estudios Históricos, 1910-1936. Marcial Pons, Madrid.

MaIer, J. (2000). Historiografía de la Arqueología Matritense. Boletín de la Asociación Española de Amigos de la Arqueología, 39-40: 41-66.

MuÑoz, J.P. (2002). Notas sobre la Sociedad Arqueológica de Toledo (1883-1886). Archivo secreto: revista cultural de Toledo, 1: 274-9.

OrTiz, C. (1987): Luis de Hoyos Sáinz y la Antropología Española. Consejo Superior de Investigaciones Científicas, Madrid.

Ortiz, C. (1994): Pan Fernández, Ismael del. Diccionario Histórico de la Antropología Española. (C. Ortiz y L. A. Sánchez, eds). Consejo Superior de Investigaciones Científicas, Madrid: 538-40.

Ortiz, C. (2001): De los cráneos a las piedras. Arqueología y Antropología en España, 1874 - 1977. Compltum 12: 273-292.

Ortiz, C.; Fernández, V.M. (2009): Pan Fernández, Ismael del. Diccionario Histórico de la Arqueología Española (Siglos $X V$ - $X X$ ). (M. Díaz-Andreu, G. Mora y J. Cortadella, eds). Marcial Pons Historia, Madrid: 506-7.

Otero, L.E. (2001): La destrucción de la ciencia en España. Las consecuencias del triunfo militar de la España franquista. Historia y Comunicación Social 6: 149-189

PAN, I. DEL (1915): Noticia de hallazgos prehistóricos en tres cuevas aún no citadas de la Sierra de Cameros (Logroño). Notas de la Comisión de Investigaciones Paleontológicas y Prehistóricas, 4: 1-7.

PAN, I. DEL (1917a): Exploración de la cueva prehistórica del Conejar (Cáceres). Notas de la Comision de Investigaciones paleontologicas y Prehistoricas, 14: 1-7.

PAN, I. DEL (1918). Paleogeografía de los mamíferos cuaternarios más importantes de Europa y norte de África. Memorias de la Comisión de investigaciones paleontológicas y prehistóricas 3, Madrid.

PAN, I. DEL (1920): Hallazgos protohistóricos de la orilla derecha del Tajo en las inmediaciones de Toledo. Boletín de la Real Academia de Bellas Artes y Ciencias Históricas de Toledo, 7, 411-20.

PAN, I. DEL (1921a): Prólogo. Flora de la Rioja. Imprenta Moderna, Logroño, 7-17.

PAN, I. DEL (1921b): Sobre un dato biogeográfico observado en los alrededores de la capital riojana. Boletín de la Real Sociedad Española de Historia Natural 21:135-138

PAN, I. DEL (1922a): La edad de Cueva Lóbrega y de las de Peña Miel de la sierra de Cameros (Logroño). Actas y Memorias de la Sociedad Española de Antropología, Etnografía y Prehistoria, 1 (2-3): 129-140

PAN, I. DEL (1922b): Observaciones a un apunte folklórico de Extremadura. Actas y Memorias de la Sociedad Española de Antropología, Etnografia y Prehistoria, 1(2-3): 54-57.

PAN, I. DEL (1922c): Los exvotos de Loja. Actas y Memorias de la Sociedad Española de Antropología, Etnografía y Prehistoria, 1(2-3): 72-73

PAN, I. DEL (1922d): Totemismo entomológico. Actas y Memorias de la Sociedad Española de Antropología, Etnografia y Prehistoria, 1(2-3): 96-97

PAN, I. DEL (1922e): El yacimiento prehistórico y protohistórico de la Alberquilla. Boletín de la Real Academia de la Historia, 81: 136-52.

PAN, I. DEL (1923a): El grafito de las cercanías de Guadamur (Toledo). Boletín de la Real Sociedad Española de Historia Natural, 23: 300-302.

PAN, I. DEL (1923b): Impresiones geológicas de una excursión al Puerto del Milagro (Montes de Toledo). Boletín de la Real Sociedad Española de Historia Natural, 23: 260-265.

PAN, I. DEL (1923c): Nueva localidad de magnetita en la provincia de Toledo. Boletín de la Real Sociedad Española de Historia Natural, 22: 274-277.

PAN, I. DEL (1924): Adiciones a la geología y mineralogía del valle alto del Deva (Guipúzcoa. Boletín de la Real Sociedad Española de Historia Natural, 24: 16-27.

PAN, I. DEL (1925a): Algunos datos más para la gea toledana. Boletín de la Real Sociedad Española de Historia Natural, 25: 31-34.

PAN, I. DEL (1925b): Restos de fósiles de Prosbocídeos existentes en el Gabinete de Historia Natural del Instituto de Toledo. Boletín de la Real Sociedad Española de Historia Natural, 25: 343-352.

PAN, I. DEL (1926a): Catálogo descriptivo de una colección histórica de mármoles existente en el Instituto de Toledo. Imprenta Provincial, Toledo. 
PAN, I. DEL (1926b): Datos prehistóricos y etnológicos recogidos en algunos pueblos comarcanos de los Montes de Toledo. Actas y Memorias de la Sociedad Española de Antropología, Etnografía y Prehistoria, 45: 43-50.

PAN, I. DEL (1927): La virgen de los Alfileritos. Boletín de la Real Academia de Bellas Artes y Ciencias Históricas de Toledo, 30: 41-53.

PAN, I. DEL, (1928): Algunas supersticiones y creencias recogidas en los pueblos de Guadamur y Puebla de Montalban. Boletín de la Real Academia de Bellas Artes y Ciencias Históricas de Toledo, Separata: 1-15.

PAN, I. DEL (1929): Informe acerca del árbol simbólico de Toledo y su provincia con destino al "Jardín de España" en Marsella. Boletín de la Real Academia de Bellas Artes y Ciencias Históricas de Toledo, 40-41: 216-20.

PAN, I. DEL (1930a): Informe sobre los hallazgos prehistóricos de La Guardia. Boletín de la Real Academia de Bellas Artes y Ciencias Históricas de Toledo, 12: 99-102.

PAN, I. DEL (1930b): Memoria reglamentaria del curso académico de 1927-28. Boletín de la Real Academia de Bellas Artes y Ciencias Históricas de Toledo, 42-43, 81-8.

PAN, I. DEL (1930c). Memoria reglamentaria del curso académico de 1928-29. Boletín de la Real Academia de Bellas Artes y Ciencias Históricas de Toledo, 42-43: 89-98.

PAN, I. DEL, (1930d): Memoria reglamentaria del curso académico de 1929-30. Boletín de la Real Academia de Bellas Artes y Ciencias Históricas de Toledo, 44-45:214-27.

PAN, I. DEL (1932): Folklore Toledano. Imprenta A. Medina, Toledo.

PAN, I. DEL (1934): Nociones de ciencias naturales, Bosch, Barcelona.

PAN, I. DEL (1942): Casos de monstruosidad y anomalía observados en algunas especies de animales y plantas. Boletín de la Real Sociedad Española de Historia Natural. Sección Geológica, 40: 319-28.

PAN, I. DEL (1943): Aspectos etnológico-geográficos de Portugal (folklore hispano- portugués). Actas y Memorias de la Sociedad Española de Antropología, Etnografía y Prehistoria, 18: 5-213.

PAN, I. DEL (1944a): Recuerdo folclórico de algunas fiestas tradicionales españolas. Revista de Tradiciones Populares, 1(1/2): 188-99.

PAN, I. DEL (1944b): Devociones especiales de algunos santos (Toledo). Revista de Tradiciones Populares, 1(1/2), 2202.

PAN, I. DEL (1946a): “Azorín”, naturalista. Boletín de la Real Sociedad Española de Historia Natural. Sección Geológica., 44(1-2): 123-51.

PAN, I. DEL (1946b): Bases para un proyecto de Museo Pedagógico-Cultural de Ciencias Naturales en España. Boletín de la Real Sociedad Española de Historia Natural. Sección Geológica, 44: 261-303.

PAN, I. DEL (1946c): Don Ignacio Bolívar. Recuerdo del maestro. Boletín de la Real Sociedad Española de Historia Natural. Sección Geológica, 44: 65-75.

PAN, I. DEL (1946c): Influencia de la Real Sociedad Española de Historia Natural en la divulgación y enseñanza de las ciencias naturales. Boletín de la Real Sociedad Española de Historia Natural. Sección Geológica, Tomo extra: 2944.

PAN, I. DEL (1946d). Semblanza científica y moral de dos naturalistas riojanos. Berceo, 1: 65-80.

PAN, I. DEL (1948a): Ensayo de monografía de un pueblo serrano: Torrecilla en Cameros (Logroño). Berceo, 6: 5-28.

PAN, I. DEL, (1948b): Ensayo de monografía geográfica de un pueblo serrano: Torrecilla en Cameros (Logroño). Berceo 7: 141-60.

PAN, I. DEL, (1948c): Observaciones sobre la mitología del dragón en España. Boletín de la Sociedad Española de Antropología, Etnografia y Prehistoria, 23: 44-69.

PAN, I. DEL (1949a): Hallazgo de restos de Elphas antiquus Falc. en Logroño. Boletín de la Real Sociedad Española de Historia Natural. Sección Geológica, 47: 193-201.

PAN, I. DEL (1949b): La investigación folklórica en La Rioja: tarea que hay que realizar. Berceo, 12: 377-400.

PAN, I. DEL (1949c): La investigación folklórica en La Rioja: tarea que hay que realizar. Berceo, 13: 477-500.

PAN, I. DEL (1949d): Reseñas Científicas. Breve noticia de algunos objetos histórico-naturales del futuro Museo de la Diputación de Logroño. Boletín de la Real Sociedad Española de Historia Natural. Sec. Geológica, 47: 697-703.

PAN, I. DEL (1950a): De la cuenca del Iregua al valle del Ebro, entre Logroño y Calahorra. Berceo, 14: 69-92.

PAN, I. DEL (1950b): Observaciones geológicas sobre el yacimiento logroñés con Elephas Antiquus. Boletín de la Real Sociedad Española de Historia Natural. Sección Geológica, 48(1): 29-41.

PAN, I. DEL (1951): El límite oriental de La Rioja. Datos geográficos, geológicos y etnográficos para su fijación. Berceo, 18: 51-80.

PAN, I. DEL (1952): Aspecto etnográfico de La Rioja: Los pueblos riojanos: causas naturales y humanas determinantes del lugar que ocupan y tipos de ellos. Berceo, 25: 577-600.

PAN, I. DEL (1953a): Aspecto etnográfico de La Rioja: Los pueblos riojanos: causas naturales y humanas determinantes del lugar que ocupan y tipos de ellos. Berceo, 26: 41-72. 
PAN, I. DEL (1953b): Aspecto etnográfico de La Rioja. Los pueblo riojanos: causas naturales y humanas determinantes del lugar que ocupan y tipos de ellos. Berceo, 27: 199-226.

PAN, I. DEL (1954): Un recuerdo inédito de mi exploración de la cueva cacereña del "Conejar" (Ensayo paleoetnológico). Boletín de la Real Sociedad Española de Historia Natural. Sección Geológica, 52: 503-18.

PAN, I. DEL (1954-55): El folklore manchego en sus relaciones con el folklore nacional. Cuadernos de estudios manchegos 7: 71-82.

PAN, I. DEL (1959): Reseñas Científicas. Wernert (Paul). Un pionner médiéval de la Préhistoire: Enrique de Villena (1384-1433). Boletín de la Real Sociedad Española de Historia Natural. Sección Geológica, 57: 163-4.

PAN, I. DEL (1964): Toledo, la ejemplar. Boletín de la Real Academia de Bellas Artes y Ciencias Históricas de Toledo, 207.

PAN, I. DEL; WeRnERT, P. (1915): Interpretación de un adorno en las figuras masculinas de Alpera y Cogul: Ensayo de Etnografía comparada. Boletín de la Real Sociedad Española de Historia Natural, 3: 1-11.

PAN, I. DEL; WERNERT, P. (1916): Consideraciones acerca de una nota bibliográfica del P. A. Barreiro titulada "Un capítulo de etnografía comparada". Boletín de la Real Sociedad Española de Historia Natural, 16: 101-104.

PAN, I. DEL; Wernert, P. (1917): Datos para la cronología del arte rupestre del oriente de España Notas de la Comisión de Investigaciones Paleontológicas y Prehistóricas, 9-12.

Peiró, I.; PASAMAR, G. (1989-90): El nacimiento en España de la Arqueología y la Prehistoria (Academicismo y profesionalización, 1856-1936). Kalathos, 9-10: 9-30.

Puelles, M. DE (2001): La educación en la España del siglo XX: políticas, instituciones, logros y fracasos. En Álvarez 2001: 3-25.

RUIZ, J.M. (2005): La edad dorada del Instituto de Toledo (1900-1937). La educación de la mesocracia provincial: Almud.

RuIZ, J. (2001): Aportaciones de la Junta para Ampliación de Estudios a la renovación de la enseñanza superior en España. En Álvarez 2001: 431-55.

SAn RomÁn, F., PAn, I. DEl, Román, P.; Rey, A. (1930): Excavaciones en el circo romano de Toledo. Memorias de la Junta Superior de Excavaciones Arqueológicas, 109. 